\title{
Belief as a Non-Epistemic Adaptive Benefit
}

\author{
Rebekah Gelpi, William A. Cunningham, and Daphna Buchsbaum \\ University of Toronto
}

Although rationalization about one's own beliefs and actions can improve an individual's future decisions, beliefs can provide other benefits unrelated to their epistemic truth value, such as group cohesion and identity. A model of resource-rational cognition that accounts for these benefits may explain unexpected and seemingly irrational thought patterns, such as belief polarization.

Rationalization is often conceived of as a betrayal of epistemic truth: someone who rationalizes believes that the reasoning behind their actions or thoughts can be explained as the result of a rational process, but their inability to access the true motivations behind their behaviour leads them to draw a mistaken conclusion. In this conceptualization, a rationalizing actor is doubly irrational: not only are their actions not governed by reasoning, but they have also concocted an imaginary, if plausible, narrative that recasts them as rational.

We propose that beliefs can serve several functions, only one of which is representing epistemic truth. Cushman describes rationalization as eliciting a "useful fiction", which already gestures at a process in which an individual's representation of the world is not entirely faithful, although it is still for the purpose of improving one's future decisions and beliefs with respect to the accuracy of these representations. But these useful fictions need not be in the service of these ultimate goals; for example, shared belief is also an important element to social cohesion and group identities (Jost, Ledgerwood \& Hardin, 2008; Echterhoff, Higgins \& Levine, 2009). Sharing a belief with those in one's community is therefore beneficial not only when (and because) that belief is true, but also when (and because) it provides an individual with the benefits of a group, such as a sense of belonging and easily-accessible shared knowledge.

This belonging is not elicited by social conformity alone. Indeed, the "shared reality" generated by a community relies on its members' certainty that they believe in it on the merits of the evidence in order to fully belong (Echterhoff, Higgins \& Levine, 2009); in other words, they are rationalizing about why they hold these beliefs.
In turn, the rationalization that results in a group's system of shared belief and belonging is powerful. As a result, in order to reap the benefits of belonging, it is advantageous, and in fact rational, to ignore evidence that would require believing something that threatens one's relationship to a social group. This phenomenon is especially apparent with ideological and moral beliefs, and other beliefs that can become central to one's identity (Kruger \& Dunning, 1999; Jost et al., 2003), and they can become quite resistant to change, with members of a community dismissing contradicting evidence, and even experiencing altered memory and perceptual judgment, rather than give up on a shared belief (Van Bavel \& Pereira, 2018).

Trusting the beliefs shared by one's social group, and "outsourcing" one's own cognition to depend on knowledge held by others in their community, can also reduce the need to engage in cognitively effortful reasoning about a variety of daily needs, even those as basic as one's source of food or shelter (Sloman \& Rabb, 2016). Similarly to the heuristics and biases encountered in perceptual judgment, the reliance on shared community beliefs reflects a need to optimize one's limited resources for individual cognition and reasoning. In a variety of cognitive tasks and situations, the manifestation of biases such as anchoring, may reflect the rational use of these resources, accounting for the costs of additional computation against the diminishing improvements in outcome they provide (Lieder et al., 2018). The use of comparatively cheap heuristics may predispose humans to systemic biases in certain cases, but the cost of these biases is outweighed by the benefits of saving limited cognitive resources. 
Existing "resource-rational" approaches to modelling cognition have generally treated beliefs as valuable to the extent that they represent the world accurately. However, by accounting for the utility that beliefs can provide unrelated to their truth value, such as in providing members of a community a sense of group identity and belonging, or in their ability to bolster the effectiveness or usefulness of other elements of one's belief system, we can better understand the mechanisms that motivate people to process information in a biased fashion, and fail to update their beliefs as a result. This could allow us to clarify how phenomena that seem to defy traditional conceptualizations of rational belief, such as belief polarization-the strengthening of opposing views in two different individuals or groups after observing the same data-may be understood as the result of a resource-rational process.

The phenomenon of belief polarization leads to a calcification of increasingly extreme views that become progressively more resistant to change (Lord, Ross \& Lepper, 1979). The motivation behind failing to integrate information that goes against one's existing beliefs, or even in fortifying one's existing views against this information, appears on the surface to be irrational. However, the same biases that allow people to rely on their local majorities as a source of shared beliefs that can offer better social outcomes, are those that can predispose them to be especially motivated to maintain these beliefs, even when they are incorrect or lead to conflict. This motivation is further fortified because giving up on certain beliefs may threaten one's broader worldview or the safety of one's position within a social group; keeping certain fictions may be preferable if they improve the function of one's causal understanding of the world.

The adaptive value of beliefs, and the rationalizations that bring them about, goes beyond simply improving an individual's predictions and decisions. Beliefs can also be a formative component of an individual's self- or group-identity, to the point where it may sometimes be more rational, given limited cognitive resources, to dismiss evidence that would threaten them, than to adjust one's views to account for new data. In an increasingly polarized social climate, in which people seek out information that confirms their own views and reject data that does not fit with their a priori model of the world, fully understanding the nonepistemic motivations for maintaining beliefs in the face of negative evidence is critical to developing methods to challenge the entrenched, unquestioned thought patterns that belief polarization gives rise to.

Echterhoff, G., Higgins, E. T., and Levine, J. M. (2009). Shared reality: Experiencing commonality with others' inner states about the world. Perspectives on Psychological Science, 4(5), 496-521.

Jost, J. T., Glaser, J., Kruglanski, A. W., and Sulloway, F. J. (2003). Political conservatism as motivated social cognition. Psychological Bulletin, 129(3), 339.

Jost, J. T., Ledgerwood, A., and Hardin, C. D. (2008). Shared reality, system justification, and the relational basis of ideological beliefs. Social and Personality Psychology Compass, 2(1), 171-186.

Kruger, J., and Dunning, D. (1999). Unskilled and unaware of it: how difficulties in recognizing one's own incompetence lead to inflated self-assessments. Journal of Personality and Social Psychology, 77(6), 1121.

Lieder, F., Griffiths, T. L., Huys, Q. J., and Goodman, N. D. (2018). The anchoring bias reflects rational use of cognitive resources. Psychonomic Bulletin \& Review, 25(1), 322349.

Lord, C. G., Ross, L., and Lepper, M. R. (1979). Biased assimilation and attitude polarization: The effects of prior theories on subsequently considered evidence. Journal of Personality and Social Psychology, 37(11), 2098.

Sloman, S. A., and Rabb, N. (2016). Your understanding is my understanding: Evidence for a community of knowledge. Psychological Science, 27(11), 1451-1460.

Van Bavel, J. J., and Pereira, A. (2018). The partisan brain: An Identity-based model of political belief. Trends in Cognitive Sciences, 22(3), 213-224. 